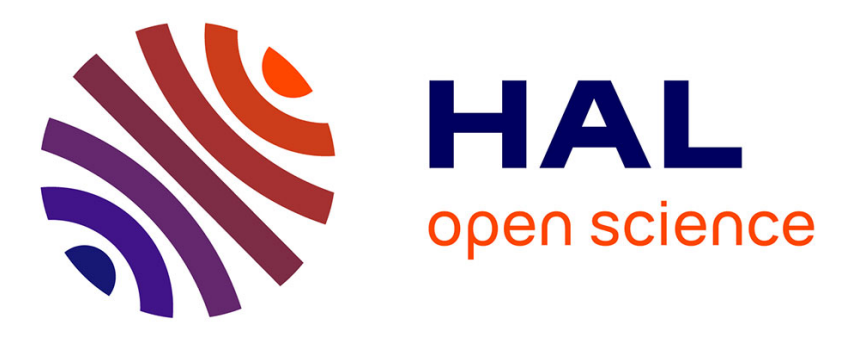

\title{
Nanosized carbon forms in the processes of pressure-temperature-induced transformations of hydrocarbons
}

V.A. Davydov, A.V. Rakhmanina, Jean-Paul Boudou, Alain Thorel, H. Allouchi, V. Agafonov

\section{To cite this version:}

V.A. Davydov, A.V. Rakhmanina, Jean-Paul Boudou, Alain Thorel, H. Allouchi, et al.. Nanosized carbon forms in the processes of pressure-temperature-induced transformations of hydrocarbons. Carbon, 2006, 44, pp.2015-2020. 10.1016/j.carbon.2006.01.012 . bioemco-00156636

\section{HAL Id: bioemco-00156636 \\ https://hal-bioemco.ccsd.cnrs.fr/bioemco-00156636}

Submitted on 22 Jun 2007

HAL is a multi-disciplinary open access archive for the deposit and dissemination of scientific research documents, whether they are published or not. The documents may come from teaching and research institutions in France or abroad, or from public or private research centers.
L'archive ouverte pluridisciplinaire HAL, est destinée au dépôt et à la diffusion de documents scientifiques de niveau recherche, publiés ou non, émanant des établissements d'enseignement et de recherche français ou étrangers, des laboratoires publics ou privés. 


\title{
Nanosized carbon forms in the processes of pressure-temperature-induced transformations of hydrocarbons
}

\author{
V.A. Davydov ${ }^{a}$, A.V. Rakhmanina ${ }^{a}$, J.-P. Boudou ${ }^{b}$, A. Thorel ${ }^{c}$, \\ H. Allouchi ${ }^{\mathrm{d}}$ V. Agafonov ${ }^{\mathrm{d}},{ }^{*}$ \\ ${ }^{a}$ L.F. Vereshchagin Institute for High Pressure Physics of the RAS, Troitsk, Moscow region 142190, Russia \\ b \\ ersité Pierre et Marie Curie, CNRS, UMR 7047, CASE 124, LGM, 4, Place Jussieu, 75252 Paris Cedex 05, France \\ ${ }^{\text {C }}$ Centre des Matériaux, UMR CNRS 7633, Ecole des Mines de Paris, BP 87, 91003 EVRY Cedex, France \\ d Université Franc ois Rabelais, E.A. CIME 2098, av. Monge 31, Tours 37200, France
}

\begin{abstract}
The products of thermal conversions of naphthalene, anthracene, pentacene, perylene, and coronene at 8 GPa in the temperature range up to $1300{ }^{\circ} \mathrm{C}$ have been studied by scanning electron and high-resolution transmission electron microscopies. As a result, it has been established that various nanometer-sized carbon species (spherical and coalesced two-core onion-like carbon particles, faceted polyhedral particles, graphitic ribbons, graphitic folds, and nanocrystalline diamonds) are present in the conversion products together with micron-sized crystallites of graphite and diamond.
\end{abstract}

Keywords: Carbon nanoparticles; High pressure; Transmission electron microscopy

\section{Introduction}

Thermal conversions of carbonaceous compounds under pressures present a complex sequence of physicochemical transformations associated with the carbonization of the original materials and the successive structural organization of the carbon residues formed. The final stages of the evolution of such systems under high pressures are the formation of graphite or diamond. Up to now, both these stages have been studied fairly comprehensively on the bulk micrometer scale level [1-10]. In such type of studies, X-ray diffraction and Raman spectroscopy, which provide for characterization of the evolution of the carbon states in some detail depending on pressure, temperature, or the duration of treatment, are usually the main

*Corresponding author. Fax: +33 247367144.

E-mail address: agafonov@univ-tours.fr (V. Agafonov). methods of investigations of carbon materials. Microscopic investigations of the materials by scanning (SEM) and highresolution transmission electron microscopy (HRTEM) normally play an ancillary role. In the study of graphitization, they illustrate the processes of the lateral growth of graphene layers, the increase of the number of the parallel graphene layers and their structural ordering in the layer packing, and the change of the microtexture of the material as a whole $[3,4,6]$. In the case of diamond formation, they allow a clear demonstration of the size, composition, and morphology of crystals of the diamond fractions obtained $[8,10]$.

At the same time, theoretical investigations of the problems of the relative stability of the different nanometersized carbon structures [11-16] have shown that the initial nanosized stages of the structural organization of the carbon residue can be accompanied by the formation not only of graphite and diamond, but also of other forms of 
carbon. According to the thermodynamic analysis carried out by several authors using different approaches [11-16], a number of the size-dependent phase transitions between the various nanostructures of carbon can take place in the products of carbonization. Usually, fullerenes, spherical onion-like and polyhedral particles, bucky diamond, diamond and graphite nanoparticles are considered as such nanoforms of carbon [11-16]. Therewith, the existence of sized ranges of thermodynamic stability is predicted almost for each of these nanoforms of carbon in fairly wide intervals of $\mathrm{p}$, T-parameters. Taking into account this fact and the substantial "kinetic" stability of the nanostructures, it can be expected that some nanostructures formed at high pressures and temperatures can be separated at ambient conditions. In the present study we have shown experimentally the possibility of the formation of different carbon nanostructures in the processes of the thermal conversions of aromatic polycyclic hydrocarbons (PAHs) at high pressures and temperatures.

The investigation of high-pressure high-temperature (HPHT) transformations of PAHs at $8 \mathrm{GPa}$ on the bulk micrometer-sized scale was carried out by us previously [10]. It was shown that the main product of HPHT treatment of naphthalene, anthracene, pentacene, perylene, and coronene at $8 \mathrm{GPa}$ and temperatures above $\sim 1100{ }^{\circ} \mathrm{C}$ is graphite with a high degree of crystalline perfection. At treatment temperatures of $1280{ }^{\circ} \mathrm{C}$ and higher, diamond becomes the main product of the conversion for all hydrocarbons investigated. Subsequent microscopic investigation allowed us to establish that in addition to graphite and diamond the products of PAHs treatment contain minor fractions of different nanometer-sized forms of carbon, which became the subjects of this study.

\section{Experimental}

High-pressure states, obtained as a result of naphthaline, anthracene, pentacene, perylene, and coronene treatment at $8 \mathrm{GPa}$ and different temperatures up to $1300{ }^{\circ} \mathrm{C}$ in a “'Toroid”-type high-pressure apparatus, were quenched under pressure to room temperature and then studied at ambient conditions by $\mathrm{X}$ ray diffraction, Raman spectroscopy, SEM, and HRTEM. Experimental details of HPHT treatment, X-ray and Raman studies were described previously [10]. Microscopic investigations of the samples were carried out by using a DSM 982 Gemini (Zeiss) scanning electron microscope. A HRTEM study was performed on a FEI F-20ST (Philips) field emission gun transmission microscope equipped with super-twin polar pieces and operated at $200 \mathrm{kV}$. Images were recorded at approximately Scherzer defocus on a CCD multiscan camera after astigmatism corrections, and eventually filtered via the Digital Micrograph software. Materials for HRTEM investigations, prepared by ultrasonic dispersion of the samples in ethanol for $5 \mathrm{~min}$, were deposited on a copper grid coated with holey carbon. The deposited suspensions were thereafter dried in air any electron irradiation damage that could induce allotropic transformations of carbon materials and, in particular, gives rise to the formation of onion-like carbon (OLC) particles [17], we used a reduced beam intensity. Since we observed no changes in the carbon structures studied during the whole period of the irradiation of the samples, we believe that the formation of different carbon nanostructures observed by us takes place not in the electron microscope but immediately in the highpressure apparatus during the process of thermal conversions of the hydrocarbons.

\section{Result and discussion}

The high-pressure states obtained as a result of HPHT treatment of different PAHs at $8 \mathrm{GPa}$ and $1280{ }^{\circ} \mathrm{C}$ were studied most extensively. Preliminary investigations of these samples by X-ray diffraction, Raman spectroscopy, and SEM showed that the micron-sized formations of graphite and diamond are their basic components regardless of the structure of the initial hydrocarbons. According to the SEM data, the diamond fraction consists of the diamond crystallites with the sizes of 5-40 pm (Fig. 1(A)). Graphite platelets with rounded edges constitute the graphite fraction. Typical lateral sizes of the graphite particles are equal to $3-30 \mu \mathrm{m}$. The main reason for the simultaneous presence in the samples of two basic carbon states is the availability of detectable axial and radial gradients of temperature in the highpressure apparatus used. For this reason, the pure diamond fraction is concentrated in the hottest part of reaction zone where the temperature matched its nominal value of $1280{ }^{\circ} \mathrm{C}$.

Subsequent detailed microscopic investigations revealed that, besides bulk graphite and diamond, various nanometersized carbon forms are present in the samples. These nanoforms of carbon manifest themselves microscopically in the form of individual globules and aggregates (Fig. 1(B)). Study of these formations by HRTEM allow imaging of a number of the most characteristic nanostructures of carbon being incorporated into the observed globules and aggregates (Fig. 2).

According to Fig. 2, the separated lighter fractions of the dispersed samples consist, as a rule, of matrixes of nonorganized carbon with inclusions of spherical OLC and coalesced two-core OLC particles, faceted polyhedral particles, graphitic ribbons, arched graphene sheets or graphitic folds, and nanocrystalline diamonds.

Typical sizes of the spherical OLC particles are equal to 15$30 \mathrm{~nm}$. The two-core OLC particles are of approximately 5-10 x 20-30 nm size, and polyhedral particles of about $7-10 \mathrm{~nm}$ size. The graphite ribbons built of packings of graphene layers with the numbers of layers ranging from 4-7 up to 20-35 show a length of several tens of nm. The $0.34 \mathrm{~nm}$ spacing of lattice fringes observed in Fig. 2(D) is a little more than that for the (002) planes of perfect graphite. The sizes of diamond nanoparticles are 3-8 nm. These diamond nanoparticles have shown different orienta- 

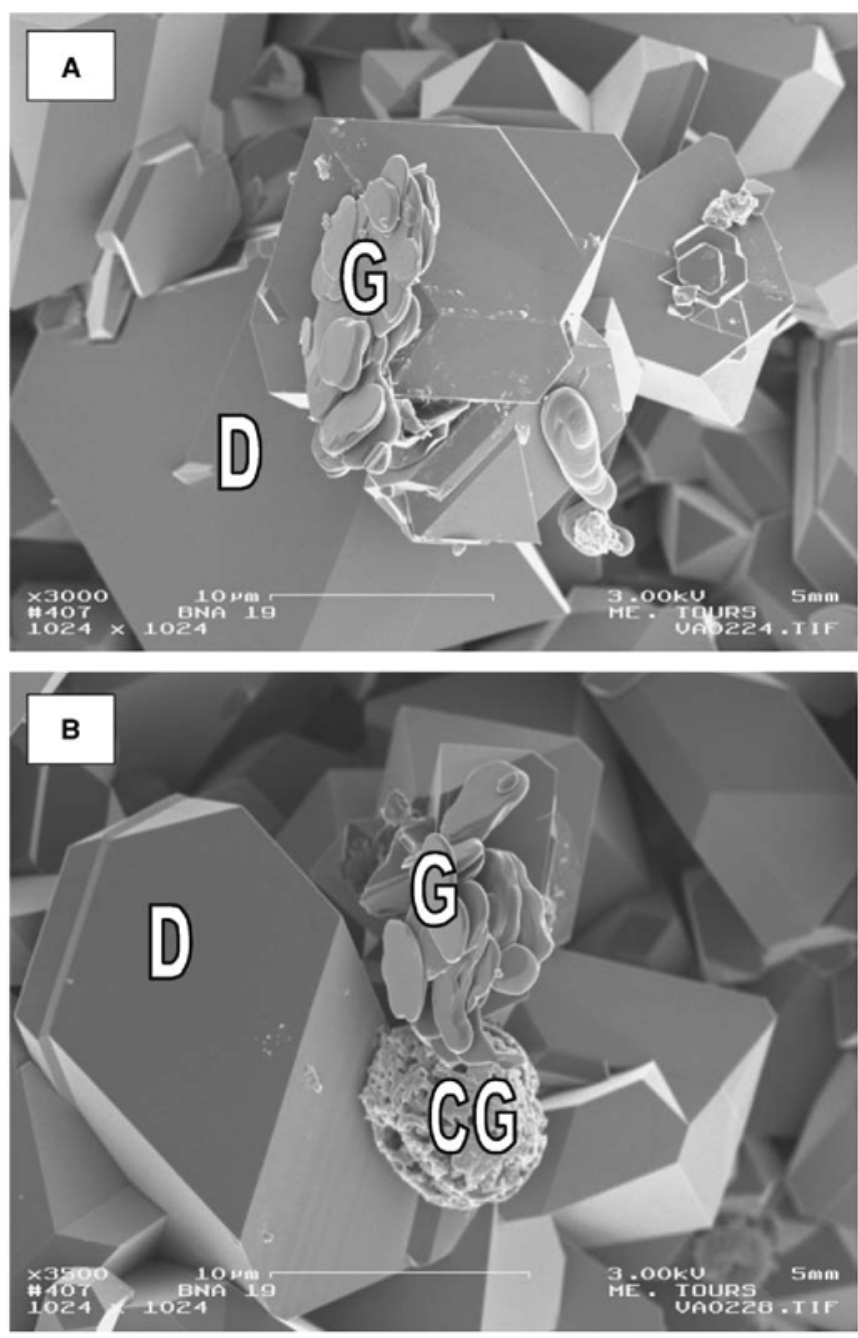

Fig. 1. SEM micrographs of the sample obtained through naphthalene treatment at $8 \mathrm{GPa}$ and $1280{ }^{\circ} \mathrm{C}$ : D—diamond, G—graphite, CG-carbon globule.

tions. The rectangle in Fig. 2(F) outlines the lattice fringes corresponding to the (111) planes of diamond structure. The spacing of lattice fringes in this case is equal to $0.21 \mathrm{~nm}$, which is also a little more than the interplane distance $\left(d_{11}=0.206 \mathrm{~nm}\right)$ for the structure of bulk diamond.

A characteristic feature of the diamond nanoparticles formed as a result of the thermal conversions of PAHs at $8 \mathrm{GPa}$ is the absence of shells, built from $\mathrm{sp}^{2}$-bonded carbon atoms, on their surface. Such shells are rather typical for diamond nanoparticles produced by other methods $[18,19]$. In other words, we did not detect the presence of "bucky diamond", - the diamond nanoparticles enclosed into a graphene envelope. Such particles, which are intermediate states between the OLC and diamond nanoparticles, are sometimes considered as an individual form of carbon [15]. However, the possibility of bucky diamond formation in the products of the thermal conversions of hydrocarbons cannot be entirely ruled out on basis of selective microscopic observations. We also did not observe the presence of fullerenes among the nanosized products of the transformations. The reason for this could be the high tem peratures of the treatment of the samples $\left(1000-1280{ }^{\circ} \mathrm{C}\right)$, being substantially higher than the limit of thermal stability of the most stable fullerene form $\left(\mathrm{C}_{60}\right)$, which is equal under pressure to $-750{ }^{\circ} \mathrm{C}$.

At the same time, the microscopic investigations showed that the structural ordering of the carbon residue formed as a result of the carbonization of hydrocarbons under high pressures is indeed accompanied by the formation of different nanoscale forms of carbon which can persist at ambient conditions. Although, it is worth noting that we did not observe stringent one-to-one correspondence between the experimental and theoretically predicted size ranges for the existence of different nanoparticles. Thus, the size range of the observed diamond nanoparticles (3-8 nm) closely corresponds to the theoretically predicted size range (2$13 \mathrm{~nm}$ ) of the stability of these nanoparticles for the temperature interval of $0-1500 \mathrm{~K}$ at zero pressure [11-16]. However, the sizes of the observed OLC particles (15$30 \mathrm{~nm}$ ) are substantially higher than the theoretically predicted upper size limit (2 nm) for the OLC particles existence $[15,16]$. It is yet possible that this discrepancy is associated with the certain structural distinctions of the real and model OLC particles, because unlike the ideal OLC particle considered in theory the real OLC particle can be a defected structure. Furthermore, in this experimental study the formation of nanostructures takes place at pressures much higher than the $0 \mathrm{GPa}$ used in theoretical considerations.

It is known that the OLC particles can be formed under intensive electron irradiation of amorphous carbon or carbon nanotubes [17], high-temperature annealing of diamond nanoparticles [18] or carbon soot [20] in vacuum, and high-dose carbon ion implantation into a metal substrate [21]. The formation of OLC particles was also noted in the graphitization process of diamond nanoparticles at pressures of 2-5 GPa [22].

The formation of OLC particles at higher pressures has so far been observed only in the experiments associated with the melting of graphite and diamond under the action of laser irradiation at 5-30 GPa and 5000-6000 ${ }^{\circ} \mathrm{C}$ [23] or in the experiments on the sublimation of amorphous acetylene black and subsequent condensation of gaseous carbon in the processes of high-temperature shock compression [24]. In these cases, it was supposed [24] that the regular concentric arrangements of graphitic layers in the OLC spherules were formed toward the centre of the nanoparticle through a process of solidification of a liquid droplet.

Under the conditions of our experiments the temperature value did not exceed $1300{ }^{\circ} \mathrm{C}$. It is therefore clear that the above-mentioned liquid-phase mechanism of the formation of OLC particles cannot be realized. In this case, the most probable mechanisms of the formation of nanoparticles are a solid-phase (short-range) or combined vaporsolid-phase (long-range).

In our opinion, the reason for the appearance of the various carbon nanoforms lies in the complicated fractional 

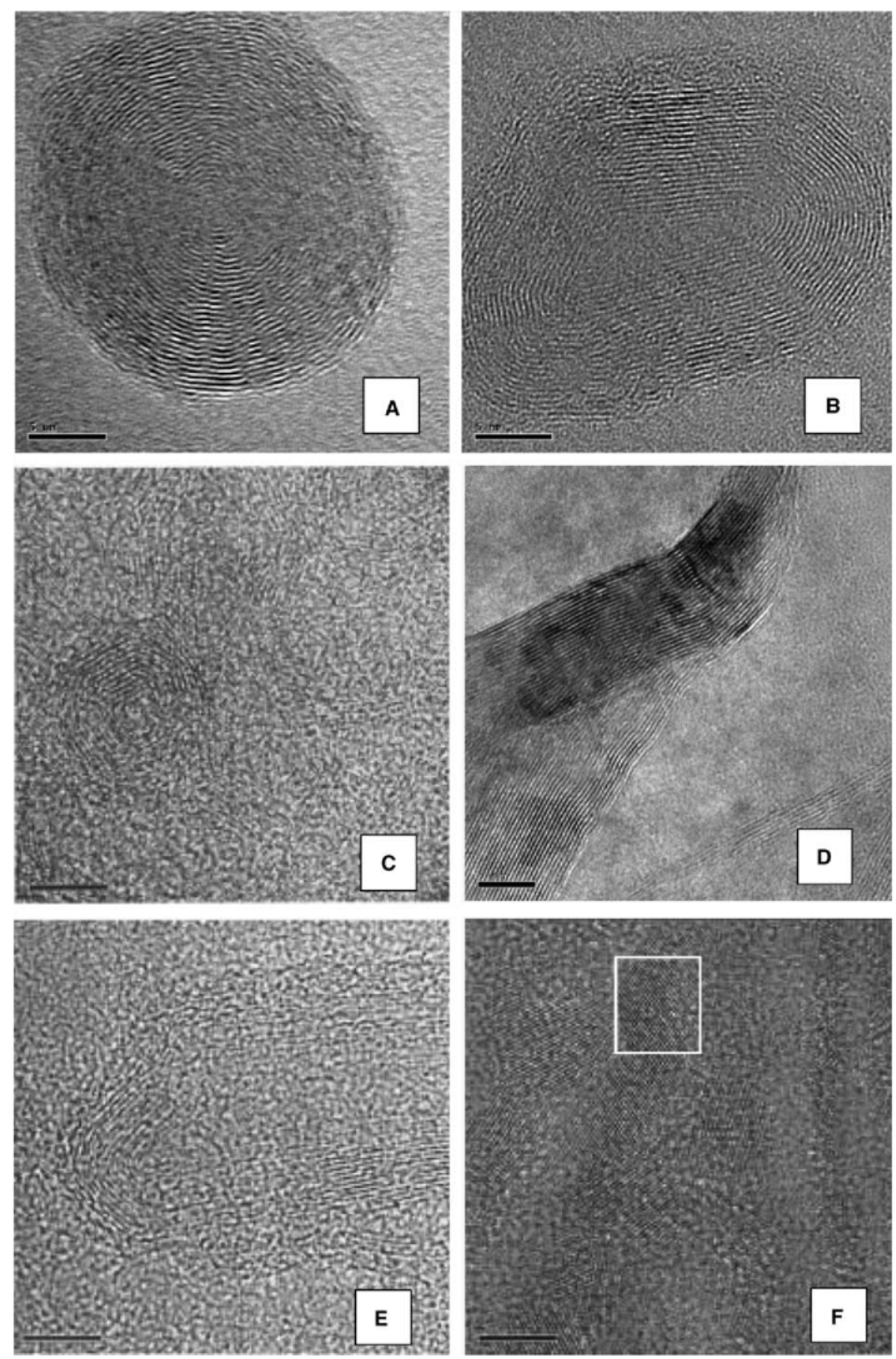

Fig. 2. HRTEM images of nanosized carbon structures observed in the sample obtained through naphthalene treatment at 8 GPa and $1280{ }^{\circ} \mathrm{C}$ : spherical onion-like (A) and coalesced two-core onion-like (B) carbon particles, faceted polyhedral particles (C), graphitic ribbons (D), arched graphene sheets (E), and nanocrystalline diamonds (F).

composition of the carbon residue formed during the final stages of hydrocarbon carbonization. Analysis of the carbonization products showed that they present complex mixtures of the ordered and disordered carbon fractions with different ratio of isolated tiny fragments of graphene layers, small packing from several graphene layers, and nonorganized carbon. At $8 \mathrm{GPa}$ and treatment temperatures over $1000{ }^{\circ} \mathrm{C}$, the carbon fractions containing graphene fragments develop alongside the formation of micrometer-sized graphite particles that are transformed into diamond at temperatures above $1280{ }^{\circ} \mathrm{C}$ [10]. Under these conditions, the main part of non-organized carbon is used for the formation of bulk graphite and diamond. But a portion of this non-organized carbon can become a medium for the formation of different nanostructures.

In this research we did not discover a close relationship between the fractional composition of the nanosized carbon formations and the nature of the original hydrocar- 
bon. It is clear that the final answer to this question requires significantly more microscopic investigations.

It is interesting to note that we have found the formation of diamond nanoparticles in the products of naphthalene treatment at $1150{ }^{\circ} \mathrm{C}$. This means that the formation of diamond nanoparticles can take place at a temperature lower than the initial temperature of the bulk synthesis of diamond microcrystallites at $8 \mathrm{GPa}$, which according to our data is equal to $1280{ }^{\circ} \mathrm{C}$. This fact testifies that under the conditions of our experiments the diamond nanoparticles formed at temperatures lower than the temperature threshold of the beginning of bulk diamond synthesis do not become the nuclei for the growth of micrometer-sized diamond crystallites. A possible reason for this phenomenon is the size-dependent phase transition of the diamond nanoparticles into graphite during the process of further growth when their sizes will exceed the stability size limit for the diamond nanoparticles. According to recent theoretical estimation [16], the upper limit size values for nanodiamond particle stability are equal to 5-15 $\mathrm{nm}$ depending on temperature.

In this situation it is possible to suggest the existence of two mechanisms for diamond formation. The first, presumably the solid-phase one, is associated with the formation of diamond nanoparticles $(3-8 \mathrm{~nm})$ from a non-ordered and low-ordered nanosized carbon fractions. The second, presumably the combined vapor-solid-phase one, is realized through the formation of diamond crystallites of micron sizes $(5-40 \mu \mathrm{m})$ from highordered graphite particles if some quantity of hydrogen is available in the system.

Taking into account that the $\mathrm{p}, \mathrm{T}$ parameters for direct noncatalytic graphite-diamond transition [7,25-27] are substantially higher than those for diamond formation from hydrocarbons, it is possible to assume that the "catalytic" action of hydrogen is connected with (i) its assistance in the formation of nuclei for growth of the bulk diamond: through the hydrogenation of the carbon atoms of graphene planes and their conversion from $\mathrm{sp}^{2}$ to $\mathrm{sp}^{3}$ states and (ii) its participation in the gaseous transfer of carbon atoms from the edge positions of graphene planes onto the growing facets of diamond. Circumstantial evidence of the possibility of hydrogen participation in this type of etching of graphene planes is the oval morphology of graphite particles shown in Fig. 1. It is possible that the availability of hydrogen in the system also promotes the growth of extensive carbon nanostructures such as graphitic ribbons. Their growth mechanism through the gaseous transport of carbon atoms can be similar to the mechanism of high-temperature growth of graphitic ribbons and polyhedral graphitic particles suggested earlier [28].

\section{Acknowledgement}

This work was partially supported by RFBR (Grant No. 0303-32640), by Scientific exchange grants from CNRS and the RAS, and in part by Award No RUE2-2659-
MO-05 of the US Civilian Research and Development Foundation for the Independent States of the Former Soviet Union (CRDF). VAD is also grateful for financial support from ' Le Studium”, Agency for Research and Hosting Foreign associated Researchers in the Centre region (France).

\section{References}

[1] Noda T, Kato H. Heat treatment of carbon under high pressure. Carbon 1965;3(3):289-97.

[2] Whang PW, Dachille F, Walker Jr PL. Pressure effects on the structure of carbons produced from anthracene. High Temp-High Press 1974;6(2):137-47.

[3] Inagaki M, Oberlin A, De Fonton S. Texture change in hard carbon on heat treatment under pressure. High Temp-High Press 1977;9(4):453-60.

[4]De Fonton S, Oberlin A, Inagaki M. Characterization by electron microscopy of carbon phases (intermediate turbostratic phase and graphite) in hard carbons when heat-treated under pressure. J Mater Sci 1980;15:909-17.

[5] Ayache J, Oberlin A, Inagaki M. Mechanism of carbonization under pressure. Carbon 1990;28(2):337-51.

[6] Beyssac O, Brunet F, Petitet JP, Goffe B, Rouzaud JN. Experimental study of the microtextural transformations of carbonaceous materials under pressure and temperature. Eur J Miner 2003;15:937-51.

[7] Wentorf RH. The behaviour of some carbonaceous materials at very high pressures and high pressures and high temperatures. J Phys Chem 1965;69(9):3063-9.

[8] Yakovlev EN, Voronov OA, Rakhmanina AV. Diamond synthesis from hydrocarbons. Sverkhtverd Mater 1984;59(4):8-11 [in Russian].

[9] Onodera A, Suito K. Synthesis of diamond from carbonaceous materials. In: Manghanani MN, Nellis WJ, Nicol MF, editors. Science and technology of high pressure. Proceedings of AIRAPT17. Hyderabad, India: Universities Press; 2000. p. 875-80.

[10] Davydov VA, Rakhmanina AV, Agafonov V, Narymbetov B, Boudou JP, Szwarc H. Conversion of polycyclic aromatic hydrocarbons to graphite and diamond at high pressures. Carbon 2004;42(2):261-9.

[11] Chaykovsky EF, Rosenberg GKh. Phase diagram of carbon and a possibility of diamond synthesis at low pressures. Russ Doklady Akademii Nauk SSSR 1984;279(6):1372-5.

[12] Badziag P, Verwoerd WS, Ellis WP, Greiner NR. Nanometer-sized diamonds are more stable than graphite. Nature 1990;343(6254): 244-5.

[13] Terrones H, Terrones M. The transformation of polyhedral particles into graphite onions. J Phys Chem Solids 1997;58(11):1789-96.

[14] Fugaciu F, Hermann H, Seifert G. Concentric-shell fullerenes and diamond particles: a molecular-dynamics study. Phys Rev B 1999;60(15):10711-4.

[15] Barnard AS, Russo SP, Snook IK. Coexistence of bucky diamond with nanodiamond and fullerene carbon phases. Phys Rev B 2003;68(7):073406(4).

[16] Jiang Q, Chen ZP. Thermodynamic phase stabilities of nanocarbon. Carbon 2005;44(1):79-83.

[17] Ugarte D. Curling and closure of graphitic networks under electron-beam irradiation. Nature 1992;359(6397):707-9.

[18] Kuznetsov VL, Chuvilin AL, Butenko YV, Mal'kov IY, Titov VM. Onion-like carbon from ultra-disperse diamond. Chem Phys Lett 1994;222(4):343-8.

[19] Tomita S, Sakurai T, Ohta H, Fujii M, Hayashi S. Structure and electronic properties of carbon onions. J Chem Phys 2001;114(17): 7477-82.

[20] De Heer WA, Ugarte D. Carbon onions produced by heat treatment of carbon soot and their relation on the $217.5 \mathrm{~nm}$ interstellar absorption feature. Chem Phys Lett 1993;207(4-6):480-6. 
[21] Cabioc'h T, Riviere JP, Delaford JJ. A new technique for fullerene onion formation. Mater Sci 1995;30(19):4787-92.

[22] Qian J, Pantea C, Huang J, Zerda TW, Zhao Y. Graphitization of diamond powders of different sizes at high pressure-high temperature. Carbon 2004;42(12-13):2691-7.

[23] Weathers MS, Bassett WA. Melting of carbon at 50-300 kbar. Phys Chem Miner 1987;15(2):105-12.

[24] Yamada K, Kunishige H, Sawaoka AB. Formation process of carbine by shock compression. Naturwissenschaften 1991;78(6): 450-2.

[25] Bundy FP. Direct conversion of graphite to diamond in static pressure apparatus. Science 1962;137(3535):1057-8.
[27] Vereshchagin LF, Ryabinin ON, Semertsan AA, Lifsfits LD, Demyashkevich BP, Popova SV. Direct graphite-diamond transformation at high static pressures. Russ Dokl Acad Nauk SSSR 1972;206(1): 78-9.

[28] Endo S, Idani N, Oshima R, Takano KJ, Wakatsuki M. $\mathrm{X}$-ray diffraction and transmission-electron microscopy of natural polycrystalline graphite recovered from high pressure. Phys Rev B 1994;49(1): 22-7.

[29] Kuznetsov VL, Butenko YuV, Zaikovskii VI, Chuvilin AL. Carbon redistribution processes in nanocarbons. Carbon 2004;42(5-6): 1057-61. 